\title{
Bacterial immunostat: Mycobacterium tuberculosis lipids and their role in the host immune response
}

\author{
Adriano Queiroz ${ }^{[1],[2]}$ and Lee W. Riley ${ }^{[1]}$
}

[1]. Divisão de Doenças Infecciosas e Vacinologia, Escola de Saúde Pública, University of California, Berkeley, USA.

[2]. Laboratório Avançado de Saúde Pública, Instituto Gonçalo Moniz, Fundação Oswaldo Cruz, Salvador, Bahia, Brasil.

\begin{abstract}
The lipid-rich cell wall of Mycobacterium tuberculosis is a dynamic structure that is involved in the regulation of the transport of nutrients, toxic host-cell effector molecules, and anti-tuberculosis drugs. It is therefore postulated to contribute to the longterm bacterial survival in an infected human host. Accumulating evidence suggests that $M$. tuberculosis remodels the lipid composition of the cell wall as an adaptive mechanism against host-imposed stress. Some of these lipid species (trehalose dimycolate, diacylated sulphoglycolipid, and mannan-based lipoglycans) trigger an immunopathologic response, whereas others (phthiocerol dimycocerosate, mycolic acids, sulpholipid-1, and di-and polyacyltrehalose) appear to dampen the immune responses. These lipids appear to be coordinately expressed in the cell wall of $M$. tuberculosis during different phases of infection, ultimately determining the clinical fate of the infection. This review summarizes the current state of knowledge on the metabolism, transport, and homeostatic or immunostatic regulation of the cell wall lipids, and their orchestrated interaction with host immune responses that results in bacterial clearance, persistence, or tuberculosis.
\end{abstract}

Keywords: Mycobacterium tuberculosis. Lipids. Immune response.

\section{INTRODUCTION}

Tuberculosis remains an important underlying cause of death from lung disease worldwide. Exposure to Mycobacterium tuberculosis, a causative agent of tuberculosis, can result in immediate clearance, establishment of latent tuberculosis infection, a rapidly progressive disease, or reactivation disease ${ }^{1}$. More than $90 \%$ of otherwise healthy individuals who become newly infected with $M$. tuberculosis do not develop an active disease $^{1}$. However, about $60 \%$ fail to eliminate the bacteria and they may remain infected for life ${ }^{1}$. It is currently not known why only a subset of those with latent tuberculosis infection progresses to develop active disease. Progression from latent infection to active disease mostly occurs in individuals without any obvious conditions related to the host. Furthermore, a subset of those who develop tuberculosis and complete a course of treatment will relapse. In human, the rate of relapse varies between $8-13 \%$, depending on the prevalence of multidrugresistant tuberculosis (MDRTB) in that population'2. Various M. tuberculosis factors, as well as host factors, have been proposed to affect these clinical outcomes, but in this review,

Corresponding author: Dr. Lee W. Riley.

e-mail: 1wriley@berkeley.edu

Received 15 June 2016

Accepted 22 November 2016 we discuss the possible role of M. tuberculosis cell wall lipids in determining these outcomes.

During a pulmonary infection, aerosolized $M$. tuberculosis enters the lungs and encounters the alveolar air space. The alveolar air space is shaped by type I and II pneumocytes. Type I pneumocytes cover about $96 \%$ of the alveolar surface area, whereas type II cells cover about $4 \%{ }^{3}$. Traditionally, it was thought that $M$. tuberculosis is engulfed by alveolar macrophages after entering the lungs, but the cellular architecture of the alveolar space suggests that $M$. tuberculosis will most likely interact with these pneumocytes first ${ }^{3}$. Later, macrophages and lymphocytes migrate to the site of infection and form a granuloma (reviewed in) ${ }^{4}$.

One unique feature of M. tuberculosis is its lipid-rich envelope (Figure 1) $)^{5,6}$. About $40 \%$ of its cell-wall dry weight is comprised of lipids and, as such, a large portion of the coding capacity of the bacterial genome is devoted to lipid biosynthesis and degradation ${ }^{7}$. Several cell wall lipids are associated with a distinct host innate immune response during the early phase of infection. Differential expression of these lipids determines whether or not M. tuberculosis will enter a chronic phase of infection.

The ability of M. tuberculosis to persist within a host appears to rely on its beta-oxidation and glyoxylate metabolic cycles. In mouse, the bacterium utilizes fatty acids as an exclusive carbon source ${ }^{8}$. During the beta-oxidation cycle, even chain fatty acids are catabolized into acetyl coenzyme A (acetyl-CoA), and odd chain fatty acids into acetyl-CoA and 


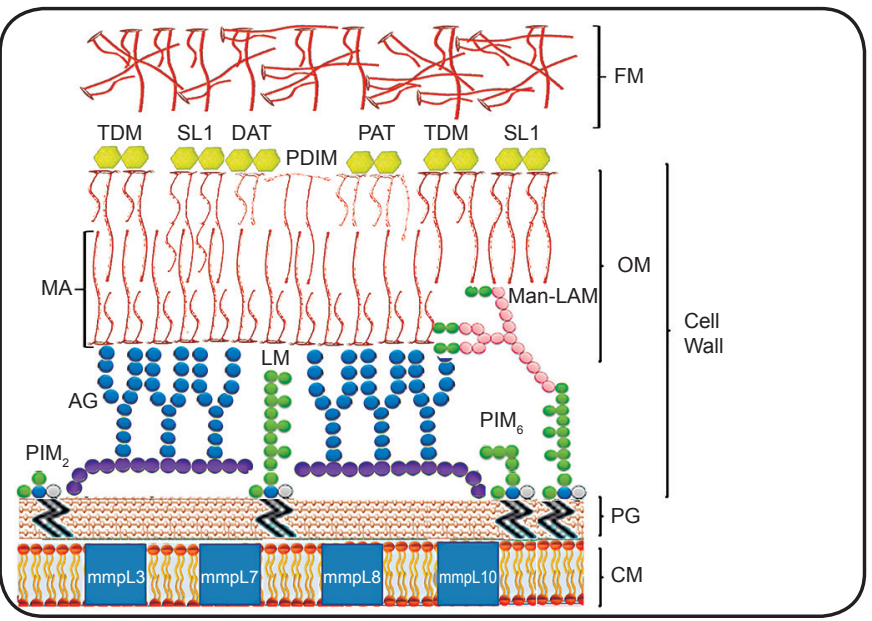

FIGURE 1 - Schematic representation of the cell envelope of Mycobacterium tuberculosis $s^{5,6}$. The components include CM, PG, and covalently attached macromolecules: AG, $\mathrm{PIM}_{2}, \mathrm{PIM}_{6}, \mathrm{LM}$, and Man-LAM; an OM composed of MA covalently attached to AG, TDM, DAT, PAT, PDIM, and SL-1; and an outermost layer of FM; FM: free mycolic acid; TDM: trehalose dimycolate; SL-1: sulphoglycolipid; DAT: diacyltrehalose; PDIM: phthiocerol dimycocerosate; PAT: poliacyltrehalose; MA: mycolic acid; Man-LAM: mannose-capped lipoarabinomannan; OM: outer membrane; AG: arabinogalactan; LM: lipomannan; PIM : phospho-myo-inositoldimannoside; PIM 6 : phospho-myo-inositol-hexamannoside; PG: peptidoglycan; CM: cell membrane; mmpL: mycobacterial membrane protein large.

propionyl-CoA $\mathrm{A}^{8,9}$. The bacillus prevents toxic accumulation of propionyl-CoA by synthesizing methylmalonyl-CoA-based lipids [phthiocerol dimycocerosate (PDIM), sulpholipid-1 (SL-1), and di- and polyacyltrehalose], as suggested by MuñozElías et al. ${ }^{10}$. Glyoxylate cycle converts acetyl-CoA molecules derived from fatty acid beta-oxidation into tricarboxylic acid cycle intermediates ${ }^{11}$. In addition, acetyl-CoA is a substrate for mycolic acid (MA), a malonyl-CoA-based lipid ${ }^{11,12}$. M. tuberculosis adjusts its lipid metabolism as it encounters limiting nutrient conditions imposed by the host. By alternatively activating the two pathways, the bacteria synthesize both methylmalonyl- and malonyl-based lipids, which allow M. tuberculosis to establish persistence.

Here, we will first review the effect of other M. tuberculosis cell wall lipids [trehalose dimycolate (TDM) and mannanbased lipoglycans] during the early, innate immunity phase of interaction with the host. Then, we will review the interaction between the products of lipid beta-oxidation and the host that becomes important during the transition into a chronic infection phase when host adaptive immunity sets in. These lipid-induced immune responses are summarized in Table $\mathbf{1}$.

\section{EARLY PHASE OF INFECTION AND MYCOBACTERIUM TUBERCULOSIS LIPID METABOLISM}

The innate immune system comprises the first line of host defense against $M$. tuberculosis. As part of this initial response, pattern recognition receptors Toll-like receptor (TLR)-2 and TLR-4 on alveolar macrophages and dendritic cells (and probably also on pneumocytes) engage in recognizing TDM (6,6'-dimycoloyl- $\alpha$-D-trehalose) and mannosylated lipoarabinomannan of $M$. tuberculosis ${ }^{13,14}$.

\section{Trehalose dimycolate}

Trehalose dimycolate, formerly referred to as cord factor, is a glycolipid where a disaccharide is linked to two mycolyl chains. Its precursor, trehalose monomycolate (TMM), has only one mycolate chain.

The cord factor has long been described as a virulence factor of M. tuberculosis. Division of the $\mathrm{H} 37$ strain into highly virulent (H37Rv) and avirulent (H37Rva) variants according to specific culture characteristics led Middlebrook et al. ${ }^{15}$ to link bacterial morphology in liquid and solid media to strain virulence. A parenteral injection of the cord factor was toxic to mice and inhibited leukocyte migration ${ }^{16}$. The toxic compound was later identified as $\mathrm{TDM}^{17}$. Injection of TDM into mouse lungs elicited granulomatous response ${ }^{18}$.

Cell wall MAs are normally covalently linked to other molecules, such as TDM and arabinogalactan. Recently, Cantrell et al. ${ }^{19}$ and Ojha et al..$^{20}$ reported that $M$. tuberculosis cell wall contains unattached MA (free MA or FM) (Figure 1). One potential source of FM is the hydrolysis of TDM. Ojha et al. ${ }^{21}$ identified a gene Msmeg_1529 that encodes a cutinase-like serine carboxyesterase responsible for TDM hydrolysis in Mycobacterium smegmatis. The enzymatic activity of Msmeg_1529 was specific for purified TDM from M. smegmatis and M. tuberculosis ${ }^{21}$. Among seven cutinaselike proteins with esterase activities previously described in M. tuberculosis, the authors suggested that Rv3452 is a possible TDM hydrolase in M. tuberculosis because of its closest relatedness to Msmeg_152921. Indeed, it was shown later that Rv3452, and also Rv3451, share $>50 \%$ amino acid similarity with Msmeg_152922. Experiments revealed that Rv3451 is the primary TDM hydrolase in M. tuberculosis ${ }^{22}$. Thus, TDM may be one source of FM. In fact, Yang et al. ${ }^{22}$ estimated that about $20 \%$ of FM in the cell wall may be derived from the hydrolysis of TDM.

Ishikawa et al. ${ }^{23}$ showed that macrophage inducible C-type lectin (Mincle) is a receptor for mycobacterial TDM. The activation of Mincle leads macrophages to produce nitric oxide and induce the production of tumor necrosis factor (TNF) and MIP-2 (also called CXCL2), and a subsequent granuloma formation ${ }^{23}$.

An alternative model for macrophage activation involves a myeloid differentiation factor 88 (MyD88)-dependent response to $\mathrm{TDM}^{14,24,25}$. Bone marrow-derived macrophages (BMMs) from $M y D 88$-knocked out were not able to produce proinflammatory cytokines in response to TDM-coated polystyrene microspheres ${ }^{24}$. Bowdish et al. ${ }^{25}$ proposed a model, where macrophage receptor with collagenous structure (MARCO), a class A scavenger receptor, cooperates with TLR-2 and cluster of differentiation 14 (CD14) in TDM recognition and signaling to mount an efficient inflammatory response to M. tuberculosis. Using deoxyribonucleic acid (DNA) microarrays, Sakamoto et al. ${ }^{14}$ evaluated a transcriptional response of BMMs to TDM- 
TABLE 1

Mycobacterium tuberculosis lipid-induced immune response and main metabolic pathways involved in lipid synthesis.

\begin{tabular}{|c|c|c|c|}
\hline Lipids & $\begin{array}{l}\text { Features of the biosynthetic } \\
\text { pathway }\end{array}$ & Related immune responses & Induced immune activity \\
\hline Trehalose dimycolate & Not described & $\begin{array}{ll}\text { - } & \text { Inhibits leukocyte } \\
\text { migration } \\
\text { - } \\
\text { Elicits granulomatous } \\
\text { response } \\
\text { Activates macrophage } \\
\text { by C-type lectin and } \\
\text { MyD88 }\end{array}$ & Enhanced immunopathology \\
\hline Mycolic acid & $\begin{array}{l}\text { Utilizes acetyl-CoA and malonyl- } \\
\text { CoA as substrates/Beta-oxidation }\end{array}$ & $\begin{array}{ll}\text { - } & \text { Induces macrophage } \\
\text { cholesterol } \\
\text { accumulation } \\
\text { Stimulates CD1- } \\
\text { restricted T } \\
\text { cell (glycerol } \\
\text { monomycolate) } \\
\text { Not recognized by TLR- } \\
2 \text { and TLR-4 }\end{array}$ & $\begin{array}{l}\text { Mostly dampened } \\
\text { immunopathology }\end{array}$ \\
\hline Mannan-based lipids & Not described & $\begin{array}{l}\text { PIM is recognized by } \\
\text { TLR-2 } \\
\text { LM induces IL- } \\
12 \text { production and } \\
\text { apoptosis } \\
\text { LAM inhibits IL- } \\
12 \text { production and } \\
\text { modulates macrophage } \\
\text { apoptosis } \\
\text { Man-LAM is involved } \\
\text { in host defense } \\
\text { evasion; suppresses the } \\
\text { production of IL-12 and } \\
\text { TNF }\end{array}$ & $\begin{array}{l}\text { PIM and LM enhance } \\
\text { immunopathology while } \\
\text { LAM and Man-LAM dampen } \\
\text { immunopathology }\end{array}$ \\
\hline Diacylated sulphoglycolipid & $\begin{array}{l}\text { A sulpholipid-1 precursor. } \\
\text { It uses propionyl-CoA and } \\
\text { methylmalonyl-CoA as substrates. } \\
\text { Beta-oxidation }\end{array}$ & $\begin{array}{ll}- & \text { Recognized by CD1b } \\
\text { receptor } \\
\text { Stimulates expression of } \\
\text { IFN- } \gamma \text { and IL-2 in CD8 }{ }^{+} \\
\text {cells }\end{array}$ & Enhanced immunopathology \\
\hline Sulpholipid-1 & $\begin{array}{l}\text { Utilizes propionyl-CoA and } \\
\text { methylmalonyl-CoA as substrates. } \\
\text { Beta-oxidation }\end{array}$ & $\begin{array}{l}\text { Inhibits phagolysosome } \\
\text { formation } \\
\text { Inhibits macrophage } \\
\text { priming, phagocytosis } \\
\text { and IL-1 release. }\end{array}$ & Dampened immunopathology \\
\hline Phthiocerol dimycocerosate & $\begin{array}{l}\text { Utilizes both malonyl-CoA and } \\
\text { methylmalonyl-CoA as substrates/ } \\
\text { Beta-oxidation }\end{array}$ & $\begin{array}{l}\text { - } \quad \text { Plays a role in cell } \\
\text { wall permeability and } \\
\text { in protection against } \\
\text { bactericidal activity. }\end{array}$ & Dampened immunopathology \\
\hline
\end{tabular}

acetyl-CoA: acetyl coenzyme A; propionyl-CoA: propionyl coenzyme A; methylmalonyl-CoA: methylmalonyl coenzyme A; CD: cluster of differentiation; TRL: toll-like receptor; MyD88: myeloid differentiation primary response gene 88; PIM: phosphatidyl inositol; LM: lipomannan; IL: interleukin; LAM: lipoarabinomannan; TNF: tumor necrosis factor; IFN: interferon. 
coated microspheres and showed that matrix metalloproteinases (MMPs) 8, 9, 12, 13, 14, and 19, were up-regulated in a MyD88-dependent manner after stimulation with TDM. Matrix metalloproteinases are a family of enzymes implicated in tissue remodeling and chronic inflammation conditions, and are involved in granuloma formation, cavitation, and fibrous granuloma capsule breakdown ${ }^{26}$.

\section{Mycolic acids}

Originally, MAs have not been described as lipids that play a role in the early phase of immune response to infection. However, it has been since suggested that some FMs in the bacterial cell wall are derived from the hydrolysis of $\mathrm{TDM}^{22}$ and may interact with host cells to induce some type of innate immune response.

In fact, MAs are the major lipids of a protective layer of cell wall, serving as structural units of the cell wall and envelope (Figure 1). They exist in homologous series of fatty acids differing by 28 atomic mass units (a two-carbon unit). In $M$. tuberculosis, these are extremely hydrophobic $\mathrm{C}_{54}-\mathrm{C}_{63}$ fatty acids with $\mathrm{C}_{22}-\mathrm{C}_{24} \alpha$ side chains ${ }^{27}$. Three classes of M. tuberculosis MAs exist, alpha, keto, and methoxy-MA ${ }^{27,28}$; they differ in the functional groups attached to the meromycolate portion of the molecule.

Mycolic acid induces the accumulation of cholesterol inside peritoneal and alveolar macrophages. Macrophages containing cholesterol and lipid droplets resemble foamy macrophage derivatives observed in tuberculous granulomas ${ }^{29}$. Inflammatory response to intratracheal instillation of different doses of MA or TDM was compared; TDM was less effective in inducing the production of interleukin (IL)-6 and IL-12. However, TDM was very effective in inducing tumor necrosis factor alpha (TNF- $\alpha$ ), a unique property of this glycolipid. Experiments with TLR2- and TLR-4-deficient mice yielded similar results, excluding these receptors as potential pattern recognition targets of $\mathrm{MA}^{29}$. Recently, Sequeira et al. ${ }^{30}$ showed that FM can inhibit TLR-2mediated pro-inflammatory response in RAW 264.7 cells and in human lung epithelial cells (A549).

Indeed, MA may constitute a scaffold for the stimulation of CD1-restricted $\mathrm{T}$ cells by mycobacterial lipid antigens ${ }^{31}$. When the antigenicity of glycerol monomycolate (GroMM) was evaluated, the hydroxyl group of glycerol and MA chain length were shown to be critical for triggering $\mathrm{T}$ cell responses ${ }^{31}$. It was previously demonstrated that FM stimulates CD1b-restricted $\mathrm{T}$ cells, indicating that this structure might form stimulatory complexes with $\mathrm{CD} 1 \mathrm{~b}^{32}$.

Minor structural alterations of trehalose-attached MA have a profound effect on murine pro-inflammatory response. MA cyclopropane ring is required for virulence and long-term persistence of pathogenic mycobacteria in mice ${ }^{33,34}$. Also, the relative differences in the amounts of keto- and methoxy-MA influence the intra-macrophage growth rate of M. tuberculosis ${ }^{35}$ and the absence of keto- and methoxy-MA is associated with bacterial attenuation in mice ${ }^{36}$

The abundance of MA in M. tuberculosis cell wall appears to affect the course of tuberculosis in infected people. The putative mycobacterial transporter mcel might play a role in the regulation of cell wall MA abundance in M. tuberculosis. M. tuberculosis has four homologs of mce operon (mcel-4) encoding ATP-binding cassette transporters (ABC transporters) possibly involved in lipid import ${ }^{7,37,38}$. Cantrell et al. ${ }^{19}$ and Forrellad et al. ${ }^{39}$ reported that disruption of $m c e l$ operon results in a $M$. tuberculosis mutant that accumulates several-fold more FM in its cell wall than wild type bacteria. Both groups suggested that the operon might encode an importer system involved in recycling of MA. Also, disruption of the mceloperon renders the cells hypervirulent in mice $e^{40,41}$. The mutant is unable to induce a strong T-helper 1 (Th1) type T cell immune response and organized granuloma formation in lungs ${ }^{41}$. Taken together, these observations suggest that the mcel operon is involved in the remodeling of $M$. tuberculosis cell wall, dampening proinflammatory response in mouse that is associated with rapid progression to death ${ }^{40,41}$. The operon is not expressed in the wild type strain during the first 4-8 weeks of infection in mouse ${ }^{42}$, suggesting that the M. tuberculosis cell wall lipid profile can be altered according to the course and/or time of infection.

Free mycolic acid (FM), a major compound involved in biofilm formation ${ }^{20,21}$, is released from TDM at some point in late infection; the latter is recognized for its ability to activate the innate immune response ${ }^{14,23}$. At that infection stage, (1) the capacity of M. tuberculosis to induce pro-inflammatory response is diminished; (2) the bacterium becomes drug tolerant ${ }^{22}$; and (3) nutrient uptake increases as the host imposes bacterial starvation $^{22}$.

Queiroz et al. ${ }^{43}$ used high-resolution quantitative time-offlight liquid chromatography-mass spectrometry and identified 26 acyl forms of lipid species whose levels were either decreased or increased in mcel mutant compared with wild type. The mutant strain showed lower levels of different acyl forms of diacyltrehalose (DAT), diacylated sulphoglycolipids ( $\mathrm{Ac}_{2} \mathrm{SGL}$ ), PDIM, and phosphatidylethanolamine; and increased levels of acyl forms of alpha-, keto-, and methoxy-MA species and hydroxyphthioceranic acid $^{43}$. These cell wall changes appeared to profoundly affect the host response, perhaps ultimately determining the clinical outcome in an infected host.

\section{Mannan-based lipoglycans}

Cell wall-associated lipids, such as phosphatidyl-myoinositol mannosides (PIM), and the glycolipids lipomannan (LM) and lipoarabinomannan (LAM), play a key role in modulating the host response during infection by interacting with different receptors on macrophages and dendritic cells ${ }^{44}$. The structure and biosynthesis of PIM, LM, and LAM have already been reviewed ${ }^{45,46,47}$.

Much of the literature focuses on the role of these molecules in maintaining mycobacterial cell wall integrity ${ }^{48}$ and growth ${ }^{49}$, but PIMs, LM, LAM, and mannose-capped lipoarabinomannan (Man-LAM) (Figure 1) also play an important role in host defense, and hence, induction of host responses. Interestingly, LM, LAM, Man-LAM, and PIMs distinctly modulate the host immune response. Both phospho-myo-inositol-dimannoside $\left(\mathrm{PIM}_{2}\right)$ and phospho-myo-inositol-hexamannoside $\left(\mathrm{PIM}_{6}\right)$ have 
been described as agonists of TLR-2 $2^{50,51}$; Dao et al. ${ }^{52}$ showed that LM but not PIM 2 strongly induces IL-12 production and apoptosis. On the other hand, LAM inhibits IL-12 production by human dendritic cells and modulates M. tuberculosis-induced macrophage apoptosis ${ }^{53}$. Man-LAM mimics a mammalian cell mannose receptor, which enables $M$. tuberculosis to evade host defense mechanisms, inhibiting phagosome maturation by suppressing the production of IL-12 and TNF and increasing IL-10 production by dendritic cells or monocytic cells ${ }^{54}$.

Dao et al..$^{52}$ postulated that the LM: LAM ratio in the mycobacterial cell wall can directly affect the virulence of M. tuberculosis and the outcome of an infection. LM activates the inflammatory response of the host. LM, but not LAM, activates the macrophages by eliciting the expression of co-stimulatory molecules CD40 and CD86 in a TLR-2- and MyD88-dependent manner. The signaling pathway leading to cytokine production appears to be independent of TLR-4 and TLR- ${ }^{55}$. Similarly, Dao et al..$^{52}$ demonstrated that LM induces cell signaling specifically through TLR-2 ligation. Based on a structure-function evaluation, these authors suggested that the addition of arabinan to LAM masks the activity of the LM mannan core, preventing LAM from inducing apoptosis and IL-12 expression. Interestingly, although $\mathrm{PIM}_{2}$ is the lipid anchor of LM, it does not play a role in this induction. Since $\mathrm{PIM}_{2}$ contains only two mannose residues, Dao et al..$^{52}$ suggested that increased mannose content is required for the stimulation of IL-12 expression ${ }^{52}$.

Krishnan et al. ${ }^{56}$ evaluated the response of BMMs, dendritic cells, and mice to whole lipid extracts from the six major genetic lineages of M. tuberculosis and concluded that the distinct cell envelope lipid profiles affect mycobacterial virulence and immune innate response. These data reinforce the role of M. tuberculosis cell wall lipid components as a determining factor in the outcome of early phase M. tuberculosis infection.

\section{MYCOBACTERIAL LIPIDS DURING TRANSITION TO THE CHRONIC PHASE OF INFECTION}

Once M. tuberculosis survives the early assaults from antimicrobial host effector cells and molecules, it enters a chronic infection phase. This transition involves yet another set of mycobacterial lipids. The host's adaptive immune response at this stage of infection comprises the formation of $\mathrm{T}$ cell-dependent granulomas designed to contain the bacilli to prevent their spread and facilitate their elimination ${ }^{57}$. The control of $M$. tuberculosis depends on a joint effort of T cells, macrophages, and dendritic cells ${ }^{58}$, and M. tuberculosis survives within macrophages inside the granulomas. Major histocompatibility complex (MHC) class II molecules are loaded with mycobacterial peptides that are presented to CD4 $\mathrm{T}$ cells. CD8 T cell stimulation requires the loading of MHC I molecules by mycobacterial peptides in the cytosol, by egression of mycobacterial antigens into the cytosol ${ }^{59}$.

The MHC class I-like CD1 antigen-presenting molecules recognize the abundant and diverse set of lipid-containing antigens and present these amphipathic antigens for recognition to $T$ cell receptors (reviewed by Barral and Brenner ${ }^{60}$ ). Many lipid species expressed by $M$. tuberculosis can be presented by $\mathrm{CD} 1 \mathrm{a}, \mathrm{CD} 1 \mathrm{~b}$, and $\mathrm{CD} 1 \mathrm{c}$, including MA, lipoglycans (such as LAM) and PIMs, lipopeptides, mannosyl- $\beta-1$ phosphomycoketides, and sulpholipids ${ }^{60}$. Other cell wall lipids that have been described as activating/modulating the immune response include PDIM, DAT, and polyacyltrehalose (PAT) ${ }^{61}$.

Accumulating evidence suggests that the beta-oxidation pathway is a source of lipids that protect $M$. tuberculosis against host-imposed stress during the chronic phase of infection ${ }^{62}$. As described below, these lipids play a role in dampening the host immune response or protecting the tubercle bacilli against bactericidal intermediates. These beta-oxidation products include DAT, PAT, sulpholipid-1 (SL-1), and PDIM.

\section{Di-and polyacyltrehalose}

Mycobacterium tuberculosis glycolipids (DAT, PAT, and triacyltrehaloses) are located in the outer layer of the cell wall (Figure 1) and contain di- and tri-methyl branched fatty acids, only found in pathogenic species of mycobacteria. Hatzios et al. ${ }^{63}$ suggested that acyl transferase PapA3 first acylates the 2-position of one of the trehalose glucose residues with a palmitoyl group, to form trehalose 2-palmitate (T2P). A mycolipenoyl group, synthesized by the polyketide synthase Pks3/4, a product of the mas-like gene $(\mathrm{msl} 3)^{64,65}$, is then transferred to the 3-position of T2P by PapA3 to generate $\mathrm{DAT}^{66}$. DAT may either be transported to the cell surface or serve as a biosynthetic intermediate that is further elaborated with mycolipenic acids to yield PAT. Gene mmpL10, which encodes a putative lipid transporter and clusters with papA3 and $p k s 3 / 4$ genes, may encode a transporter of PAT or its precursor (Figure 1). DAT may be transported to the cell surface without further modifications ${ }^{63}$. Thus, the extracellular synthesis of PAT from DAT might constitute yet another mechanism by which M. tuberculosis protects itself against the bactericidal activities of the host during infection.

DAT extracted from M. tuberculosis H37Rv and M. fortuitum ATCC 6841 inhibits the proliferation of mouse $T$ cells in a dose-dependent manner in vitro, which suggests that this glycolipid could play a role in $\mathrm{T}$ cell hyporesponsiveness and immunosuppression associated with M. tuberculosis infections ${ }^{67}$. The disruption of the M. tuberculosis msl3 gene provided additional information about the role of polyacylated trehaloses in mycobacterial virulence. A msl3 mutant does not produce mycolipanoic and mycolipenic (phthienoic) acids required for the synthesis of DAT and PAT. In the absence of glycolipids to anchor the trehalose at the cell surface, this mutant forms bead-like aggregates with no discernable decrease in growth rate. Capsule attachment is probably defective in the mutant, and, consequently, the hydrophobic core of the wall might be exposed ${ }^{64,68}$. The $m s l 3$ mutant infects both activated and resting macrophages derived from BALB/c mice two- to fourfold more effectively than $\mathrm{H} 37 \mathrm{Rv}$, and is more efficiently taken up by the macrophages ${ }^{68}$. However, the ability of the $m s l 3$ mutant to replicate and to persist within macrophages is not altered, suggesting that DAT and PAT are unlikely involved in the survival of M. tuberculosis within phagocytic cells ${ }^{68}$. 


\section{Sulpholipid-1}

Since the discovery of sulpholipids by Middlebrook et al. ${ }^{69}$ in the early 1950s many in vivo and in vitro studies have suggested that these complex lipids play a role in the virulence of the tubercle bacillus. SL-1 comprises a trehalose-2-sulfate (T2S) core decorated with four acyl groups: a straight chain fatty acid (palmitate or stearate) and three multiply methyl-branched (hydroxy) phthioceranoic acids. The sulphotransferase Stf0 initiates SL-1 biosynthesis by sulfating the abundant disaccharide trehalose to form $\mathrm{T}_{2} \mathrm{~S}^{70}$. The acyltransferase PapA2 then catalyzes the esterification of $\mathrm{T} 2 \mathrm{~S}$ at the 2-position to generate a monoacylated intermediate monoacylated-SGL ${ }^{71}$. The polyketide synthase Pks2 synthesizes methyl-branched (hydroxy) phthioceranoyl ${ }^{65}$ and PapA1 transfers the product of Pks2 to the 3-position of monoacylated$\mathrm{SGL}$, yielding $\mathrm{Ac}_{2} \mathrm{SGL}^{71}$. MmpL8 may flip $\mathrm{Ac}_{2} \mathrm{SGL}$ across the plane of the cell membrane, allowing it to be further modified to mature SL-1 before delivery to the cell wall ${ }^{72}$ (Figure 1). Acylation of $\mathrm{Ac}_{2} \mathrm{SGL}$ with a phthioceranic acid group and another hydroxyphthioceranic acid group completed the biosynthesis of SL- $1^{70}$.

The role of $\mathrm{Ac}_{2} \mathrm{SGL}$ and SL-1 in immunopathogenesis of M. tuberculosis has been described ${ }^{73,74}$. SL-1 is the most abundant lipid on the M. tuberculosis surface and absent in nonpathogenic Mycobacterium species. SL-1 and its precursor, $\mathrm{Ac}_{2} \mathrm{SGL}$, are thus important targets in biomarkers studies.

Goren et al. ${ }^{73}$ showed that SL-1 purified from M. tuberculosis strain $\mathrm{H} 37 \mathrm{Rv}$ is a potent inhibitor of phagolysosome formation in cultured mouse peritoneal macrophages. The authors suggested that the sulfatide impairs either the phagosomal or lysosomal membranes. SL-1 also directly inhibits macrophage priming, which results in reduced superoxide anion $\left(\mathrm{O}_{2}^{-}\right)$ release, reduced phagocytosis, and reduced release of IL- $1^{75}$, and affects neutrophil signal transduction pathways ${ }^{76}$. Nevertheless, the role of SL-1 in the virulence of M. tuberculosis remains questionable ${ }^{77}$.

Kato and Goren ${ }^{78}$ showed that SL-1 damages the mitochondrial structure in synergy with TDM, but no toxic effect was noted in mice injected intraperitoneally with SL-1 alone. Later ${ }^{72,79}$, the construction of $m m p L 8$ and $p k s 2$ mutants clarified the role of SL-1 and its precursors in the pathogenesis of M. tuberculosis. MmpL8 is a member of a family of 13 predicted lipid transporters and $p k s 2$ has high homology to the mycocerosic acid synthase (mas) gene, whose product is involved in the synthesis of a class of multiple methyl-branched fatty acids ${ }^{65}$. M. tuberculosis mmpL 8 mutant is unable to produce SL-1 and accumulates $\mathrm{Ac}_{2} \mathrm{SGL}$ in the cytoplasm. The $p k s 2$ mutant that synthesizes neither SL-1 nor $\mathrm{Ac}_{2} \mathrm{SGL}$ grows at rates indistinguishable from those of the wild type in the spleen, liver, and lung, indicating that SL-1 is not required for the growth of $M$. tuberculosis in vivo. In contrast, the $m m p L 8$ mutant was attenuated in all these organs ${ }^{72}$. These results suggest that $\mathrm{Ac}_{2} \mathrm{SGL}$ is the immunogenic metabolite of the SL-1 pathway.

Gilleron et al. ${ }^{74}$ confirmed these findings by showing that $\mathrm{Ac}_{2} \mathrm{SGL}$ binds to the MHC-like lipid receptor CD1b and stimulates the expression of interferon (IFN)- $\gamma$ and IL-2 in $\mathrm{CD}^{+} \mathrm{T}$ cells obtained from tuberculin skin test-positive donors $^{74}$. Thus, since the biosynthesis of SL-1 is completed by acylation of $\mathrm{Ac}_{2} \mathrm{SGL}$ with a phthioceranic acid group and another hydroxyphthioceranic acid group, it is possible that M. tuberculosis uses these two fatty acids in a balanced fashion to modulate the host immune response to bacterial advantage ${ }^{74}$.

\section{Phthiocerol dimycocerosate}

By using signature-tagged mutagenesis (STM), Cox et al. ${ }^{80}$ isolated three $M$. tuberculosis transposon mutants unable to replicate within the mouse lung. These transposons disrupted the mas, fadD28 and $m m p L 7$ genes which encode enzymes and proteins implicated in the synthesis, assembly and, subcellular localization of $\mathrm{PDIM}^{80}$. Also, by using a cell-free system, Trivedi et al. ${ }^{81}$ delineated the enzymology of PDIM assembly and the precise roles of several proteins involved in the biosynthesis of this lipid. Some genes described as involved in PDIM synthesis are located within 50kbp pps locus ${ }^{82}$.

The observation that a PDIM-deficient $M$. tuberculosis H37Rv mutant replicates less well and elicits fewer lung surface tubercles than a PDIM-producing H37Rv strain in a guinea pig model suggested for the first time that PDIMs may play a role in M. tuberculosis pathogenesis ${ }^{83}$. In their study, Cox et al. ${ }^{80}$ also showed that $M$. tuberculosis mutant strains unable to synthetize PDIM were attenuated in mice. These strains were defective in cell wall biosynthesis, displayed strikingly altered colony morphology on solid medium, compared with the wild type, and their growth in mouse lungs was impaired ${ }^{80}$.

Phthiocerol dimycocerosate may be also involved in cell wall permeability. Insertion mutants unable to synthesize or subcellular translocation of PDIM have higher cell wall permeability and are more sensitive to detergents than the wild-type strain. Chenodeoxycholate is a negatively-charged hydrophobic probe used for the evaluation of the fluidity of mycobacterial cell wall lipids ${ }^{84}$. Its uptake by $M$. tuberculosis strain devoid of PDIM was significantly higher than in the wild type ${ }^{85}$.

Compared with mice infected with wild-type M. tuberculosis, bacterial loads in the lungs and spleen of mice over a 4-month period were reduced in animals intranasally infected with a PDIM-deficient mutant ${ }^{86}$. The differences in bacterial loads during the acute phase of infection are probably caused by a delay in granuloma formation in mice infected with PDIMdeficient mutant. M. tuberculosis PDIMs do not contribute to the inhibition of phagolysosome fusion within resting macrophages but contribute to the protection against bactericidal activity of reactive nitrogen intermediates ${ }^{86}$. Finally, the PDIM-deficient mutant induced the secretion of higher amounts of TNF- $\alpha$ and IL- 6 by macrophages and dendritic cells, 48 and $72 \mathrm{~h}$ after infection, than the wild type ${ }^{86}$. Also, Astarie-Dequeker et al. ${ }^{87}$ showed that PDIM interferes with phagocytosis and blocks phagosomal acidification in a cholesterol-dependent manner. These data suggest that M. tuberculosis uses PDIM for the modulation of the early host immune response and to dampen the bactericidal activity of macrophages ${ }^{86}$. Thus, PDIM appears to affect the infection outcome at both early and chronic phases of disease. 


\section{LIPID SYNTHESIS CONTROL AND A BACTERIAL IMMUNOSTAT}

Mycobacterium tuberculosis manages its cell wall lipid content in order to modulate the host immune response over the course of infection. Analysis of the lipid-induced immune response generated from the products of beta-oxidation pathway, suggests that DAT/PAT, SL-1, and PDIM collectively contribute to diminishing the immunopathologic response induced by $M$. tuberculosis. Jain et al. ${ }^{9}$ showed that PDIM and SL-1 syntheses are coupled via metabolic flux of a common precursor, methylmalonyl-CoA. The overexpression of methylmalonylCoA mutase, which catalyzes the conversion of the citric acid cycle intermediate succinyl-CoA to methylmalonyl-CoA, led to a decrease in the total abundance of PDIM and SL-1 in vivo; this suggested that during chronic infection, $M$. tuberculosis preferentially uses the beta-oxidation pathway and not the citric acid cycle as a source of methylmalonyl-CoA ${ }^{9}$. The beta-oxidation of even chain fatty acids exclusively yields acetyl-CoA units, while beta-oxidation of odd chain fatty acids yields both acetyl-CoA and propionyl-CoA ${ }^{10}$. Thus, during the later phase of infection and after the activation of host immune response, $M$. tuberculosis uses the beta-oxidation pathway to metabolize intracellular odd chain lipids to synthetize DAT/ PAT, SL-1, and PDIM. During this phase of infection, local immunosuppression induced by these lipids may contribute to the establishment of a long-term M. tuberculosis infection. This notion is supported by a recent study by Mendum et al. ${ }^{62}$, who showed that M. tuberculosis survival in dendritic cells depends on multi-gene loci associated with specific functional groups, such as the synthesis of PDIM, phenolic glycolipids, and SL-1, and cholesterol metabolism.

The manner in which M. tuberculosis regulates the cell wall lipid content during the course of infection and how the temporal lipid profile determines the fate of infection remain to be clarified. Perez et al ${ }^{88}$ described the possible contribution of PhoP-PhoR, a bacterial two-component signal transduction system involved in an adaptive response to a variety of stimuli. Disruption of this system markedly affects the ability of the tubercle bacillus to replicate in cellular and animal models ${ }^{88}$. PhoP positively regulates the synthesis SL-1, DAT, and PAT ${ }^{89}$. Also, Galagan et al..$^{90}$ proposed a regulatory network model that operates during hypoxia where PhoP regulates whiB3, with both PhoP and WhiB3 regulating PAT/DAT and SL-1. WhiB3 is involved in the maintenance of redox homeostasis by regulating fatty acid metabolism, and modulates the biosynthesis of PAT, DAT, SL-1, PDIM, and triacylglycerol ${ }^{91}$.

Another suggestion concerning $M$. tuberculosis cell wall homeostasis comes from studies of the putative lipid transporter system encoded by mce operons. It has been long recognized that the thickness of the cell wall of $M$. tuberculosis cells changes during stationary phase of growth ${ }^{92}$. Cantrell et al. ${ }^{19}$ and Forrellad et al.$^{39}$ independently reported increased abundance of FM in the cell wall of M. tuberculosis mcel mutants, suggesting that the increased thickness of the cell wall may be attributed to such lipids. Such cells may become impermeable to the host's effector molecules, albeit they may also experience the stress of nutrient starvation. Uchida et al. ${ }^{42}$ observed that during the first 8 weeks of infection in mouse, the mcel operon in wildtype $M$. tuberculosis is repressed by a negative transcriptional regulator Mce1R, which is similar to the constitutive lack of expression in the mcel mutant. During this nutrient-limited state, M. tuberculosis may down-regulate the propionyl-CoA/ methylmalonyl-CoA pathway involved in the synthesis of SL1, DAT, and PAT, while increasing the synthesis of MA, which has even lower pro-inflammatory activity ${ }^{8,30}$. Dunphy et al. ${ }^{93}$ proposed that the mcel operon is involved in MA import. A prolonged starvation of the cells with thickened cell wall may serve as a signal to de-repress the mcel operon to allow the importation of FM, a carbon source. The starvation signal may also trigger the synthesis of MA via the acetyl-CoA/malonylCoA pathway ${ }^{27}$. Queiroz et al ${ }^{43}$ showed that the beta-oxidation cycle might prefer the acetyl-CoA over the propionyl-CoA pathway in the mcel operon mutant, as evidenced by decreased levels of SL-1, DAT, and PDIM precursors, with a concomitant increase in MA levels. The mcel operon thus appears to play an important role in regulating MA abundance and utilization, allowing bacterial persistence (Figure 2).

In conclusion, $M$. tuberculosis appears to have developed an elaborate system for a homeostatic regulation of its cell wall lipid composition. It comprises a dynamic adaptive mechanism for the establishment of persistence in the host. Factors that disturb this homeostasis lead to disease on one side or bacterial clearance on the other. Collectively, the cell wall lipids serve

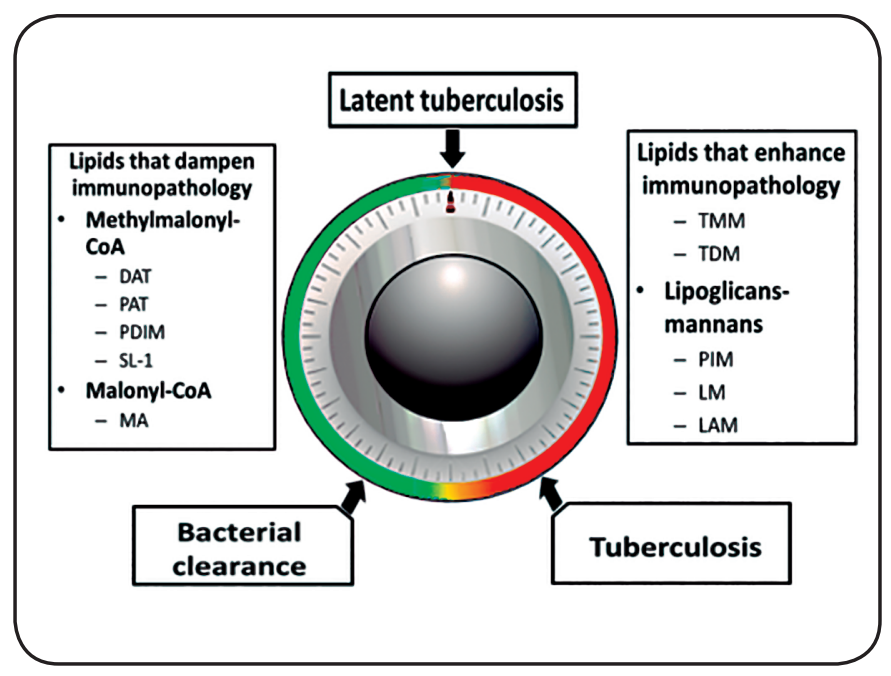

FIGURE 2 - A bacterial immunostat model of lipid-regulated host immunopathologic response.

Relative abundance of TMM, TDM, PIM, LM, and LAM in the cell wall leads to enhanced pro-inflammatory host response, while an increase in DAT, PAT, PDIM, SL-1, and MA leads to dampened immunopathologic response. Maintenance of cell wall lipid homeostasis allows Mycobacterium tuberculosis persistence in the host (latent TB infection). Disruption of this homeostasis in favor of unregulated expression of pro-inflammatory lipids ultimately leads to tuberculosis, while continued dampened response, especially in the presence of anti-Mycobacterium tuberculosis drugs, leads to bacterial clearance. DAT: diacyltrehalose; PAT: poliacyltrehalose; PDIM: dimycocerosate; SL-1: sulphoglycolipid; MA: mycolic acid; TMM: trehalose monomycolate; TDM: trehalose dimycolate; PIM: phosphatidyl-myo-inositol mannoside; LM: lipomannan; LAM: lipoarabinomannan. 
as a type of immunologic thermostat (immunostat model, as depicted in Figure 2) in an infected host. Given this model, the big questions that can be asked are, 1) Which changes in the Mycobacterium tuberculosis cell wall lipid content that occur during progression to active tuberculosis can be targeted by drugs to prevent reactivation TB in those who are latently infected? 2) What host immunological signals are recognized by Mycobacterium tuberculosis that induce the bacterium to modulate its cell wall lipid contents for its persistence? And 3) Can we identify a vaccine or an immunomodulator that can shift the equilibrium state towards elimination of the bacteria in a host? Better understanding of the interaction between M. tuberculosis lipids and the immune response could lead to the development of such immunomodulators distinct from the traditional protein antigen-based vaccines, or the development of drugs against novel targets in M. tuberculosis to tip the balance in favor of the host.

\section{Conflict of interest}

The authors declare that there is no conflict of interest.

\section{Financial support}

This work was supported in part by the Global Health Equity Scholars program, Fogarty International Center (TW009338).

\section{REFERENCES}

1. Parrish NM, Dick JD and Bishai WR. Mechanisms of latency in Mycobacterium tuberculosis. Trends Microbiol. 1998;6(3):107-12.

2. Mak A, Thomas A, Del Granado M, Zaleskis R, Mouzafarova $\mathrm{N}$, Menzies D. Influence of multidrug resistance on tuberculosis treatment outcomes with standardized regimens. Am J Respir Crit Care Med. 2008;178(3):306-12.

3. Bermudez LE, Goodman J. Mycobacterium tuberculosis invades and replicates within type II alveolar cells. Infect Immun. 1996;64 (6):1400-06.

4. Flynn JL, Chan J. Tuberculosis: latency and reactivation. Infect Immun. 2001;69(7):4195-4201.

5. Brennan PJ, Nikaido H. The envelope of mycobacteria. Annu Rev Biochem. 1995;64:29-63.

6. Brennan PJ. Structure, function, and biogenesis of the cell wall of Mycobacterium tuberculosis. Tuberculosis (Edinb). 2003;83(1-3):91-7.

7. Cole ST, Brosch R, Parkhill J, Garnier T, Churcher C, Harris D, et al. Deciphering the biology of Mycobacterium tuberculosis from the complete genome sequence. Nature. 1998;393(6685):537-44.

8. Munoz-Elias EJ, McKinney JD. Mycobacterium tuberculosis isocitrate lyases 1 and 2 are jointly required for in vivo growth and virulence. Nat Med. 2005;11(6):638-44.

9. Jain M, Petzold CJ, Schelle MW, Leavell MD, Mougous JD, Bertozzi CR, et al. Lipidomics reveals control of Mycobacterium tuberculosis virulence lipids via metabolic coupling. Proc Natl Acad Sci USA. 2007;104(12):5133-38.

10. Muñoz-Elias EJ, Upton AM, Cherian J, McKinney JD. Role of the methylcitrate cycle in Mycobacterium tuberculosis metabolism, intracellular growth, and virulence. Mol Microbiol. 2006;60(5): 1109-22.
11. McKinney JD, Höner zu Bentrup K, Muñoz-Elias EJ, Miczak A, Chen B, Chan WT, et al. Persistence of Mycobacterium tuberculosis in macrophages and mice requires the glyoxylate shunt enzyme isocitrate lyase. Nature. 2000;406(6797):735-38.

12. Gengenbacher M, Kaufmann SH. Mycobacterium tuberculosis: success through dormancy. FEMS Microbiol Rev. 2012;36(3):514-32.

13. Khoo KH, Dell A, Morris HR, Brennan PJ, Chatterjee D. Structural definition of acylated phosphatidylinositol mannosides from Mycobacterium tuberculosis: definition of a common anchor for lipomannan and lipoarabinomannan. Glycobio. 1995;5(1):117-27.

14. Sakamoto K, Kim MJ, Rhoades ER, Allavena RE, Ehrt S, Wainwright $\mathrm{HC}$, et al. Mycobacterial trehalose dimycolate reprograms macrophage global gene expression and activates matrix metalloproteinases. Infect Immun. 2013;81(3):764-76.

15. Middlebrook G, Dubos RJ, Pierce CJ. Virulence and morphological characteristics of mammalian Tubercle bacilli. J Exp Med. 1947;86(2):175-84.

16. Bloch H. Studies on the virulence of tubercle bacilli. Isolation and biological properties of a constituent of virulent organisms. J Exp Med. 1950;91(2):197-218.

17. Noll H, Bloch H, Asselineau J, Lederer E. The chemical structure of the cord factor of Mycobacterium tuberculosis. Biochim Biophys Acta. 1956;20(2):299-309.

18. Bekierkunst A. Acute granulomatous response produced in mice by trehalose-6,6-dimycolate. J Bacteriol. 1968;96(4):958-61.

19. Cantrell SA, Leavell MD, Marjanovic O, Iavarone AT, Leary JA, Riley LW. Free mycolic acid accumulation in the cell wall of the mcel operon mutant strain of Mycobacterium tuberculosis. J Microbiol. 2013;51(3):619-26.

20. Ojha AK, Baughn AD, Sambandan D, Hsu T, Trivelli X, Guerardel $\mathrm{Y}$, et al. Growth of Mycobacterium tuberculosis biofilms containing free mycolic acids and harbouring drug-tolerant bacteria. Mol Microbiol. 2008(1);69:164-74.

21. Ojha AK, Trivelli X, Guerardel Y, Kremer L, Hatfull GF. Enzymatic hydrolysis of trehalose dimycolate releases free mycolic acids during mycobacterial growth in biofilms. J Biol Chem. 2010;285(23):17380-89.

22. Yang Y, Kulka K, Montelaro RC, Reinhart TA, Sissons J, Aderem A, et al. A hydrolase of trehalose dimycolate induces nutrient influx and stress sensitivity to balance intracellular growth of Mycobacterium tuberculosis. Cell Host Microbe. 2014;15(2):153-63.

23. Ishikawa E, Ishikawa $\mathrm{T}$, Morita $\mathrm{YS}$, Toyonaga $\mathrm{K}$, Yamada $\mathrm{H}$, Takeuchi O, et al. Direct recognition of the mycobacterial glycolipid, trehalose dimycolate, by C-type lectin Mincle. J Exp Med. 2009;206 (13):2879-88.

24. Geisel RE, Sakamoto K, Russell DG, Rhoades ER. In vivo activity of released cell wall lipids of Mycobacterium bovis bacillus CalmetteGuérin is due principally to trehalose mycolates. J Immunol. 2005;174(8):5007-15.

25. Bowdish DM, Sakamoto K, Kim MJ, Kroos M, Mukhopadhyay $\mathrm{S}$, Leifer CA, et al. MARCO, TLR2, and CD14 are required for macrophage cytokine responses to mycobacterial trehalose dimycolate and Mycobacterium tuberculosis. PLoS Pathog. 2009;5 (6):e1000474.

26. Quiding-Järbrink M, Smith DA, Bancroft GJ. Production of matrix metalloproteinases in response to mycobacterial infection. Infect Immun. 2001;69(9):5661-70.

27. Takayama K, Wang C, Besra GS. Pathway to synthesis and processing of mycolic acids in Mycobacterium tuberculosis. Clin Microbiol Rev. 2005(1);18:81-101. 
28. Barry 3rd CE, Lee RE, Mdluli K, Sampson AE, Schroeder BG, Slayden RA, et al. Mycolic acids: structure, biosynthesis and physiological functions. Prog Lipid Res. 1998;37(2-3):143-79.

29. Korf J, Stoltz A, Verschoor J, De Baetselier P, Grooten J. The Mycobacterium tuberculosis cell wall component mycolic acid elicits pathogen-associated host innate immune responses. Eur J Immunol. 2005;35(3):890-900.

30. Sequeira PC, Senaratne RH, Riley LW. Inhibition of toll-like receptor 2 (TLR-2)-mediated response in human alveolar epithelial cells by mycolic acids and Mycobacterium tuberculosis mce1 operon mutant. Pathog Dis. 2014;70(2):132-40.

31. Layre E, Collmann A, Bastian M, Mariotti S, Czaplicki J, Prandi J, et al. Mycolic acids constitute a scaffold for mycobacterial lipid antigens stimulating CD1-restricted $\mathrm{T}$ cells. Chem Biol. 2009;16(1):82-92.

32. Beckman EM, Porcelli SA, Morita CT, Behar SM, Furlong ST, Brenner MB. Recognition of a lipid antigen by CD1-restricted alpha beta+ T cells. Nature. 1994;372(6507):691-94.

33. Glickman MS, Cox JS, Jacobs Jr WR. A novel mycolic acid cyclopropane synthetase is required for cording, persistence, and virulence of Mycobacterium tuberculosis. Mol Cell. 2000;5(4):717-27.

34. Rao V, Fujiwara N, Porcelli SA, Glickman MS. Mycobacterium tuberculosis controls host innate immune activation through cyclopropane modification of a glycolipid effector molecule. J Exp Med. 2005;201(4):535-43.

35. Yuan Y, Zhu Y, Crane DD, Barry 3rd CE. The effect of oxygenated mycolic acid composition on cell wall function and macrophage growth in Mycobacterium tuberculosis. Mol Microbiol. 1998;29(6):1449-58.

36. Dubnau E, Chan J, Raynaud C, Mohan VP, Lanéelle MA, Yu K, et al. Oxygenated mycolic acids are necessary for virulence of Mycobacterium tuberculosis in mice. Mol Microbiol. 2000;36(3): 630-37.

37. Casali N, Riley LW. A phylogenomic analysis of the Actinomycetales mce operons. BMC Genomics. 2007;8:60.

38. Pandey AK, Sassetti CM. Mycobacterial persistence requires the utilization of host cholesterol. Proc Natl Acad Sci USA. 2008;105(11):4376-80.

39. Forrellad MA, McNeil M, Santangelo MP, Blanco FC, García E, Klepp LI, et al. Role of the Mcel transporter in the lipid homeostasis of Mycobacterium tuberculosis. Tuberculosis (Edinb). 2014;94(2):170-77.

40. Lima P, Sidders B, Morici L, Reader R, Senaratne R, Casali N, et al. Enhanced mortality despite control of lung infection in mice aerogenically infected with a Mycobacterium tuberculosis mce1 operon mutant. Microbes Infect. 2007;9(11):1285-90.

41. Shimono N, Morici L, Casali N, Cantrell S, Sidders B, Ehrt S, et al. Hypervirulent mutant of Mycobacterium tuberculosis resulting from disruption of the mcel operon. Proc Natl Acad Sci USA. 2003;100(26):15918-23.

42. Uchida Y, Casali N, White A, Morici L, Kendall LV, Riley LW. Accelerated immunopathological response of mice infected with Mycobacterium tuberculosis disrupted in the mcel operon negative transcriptional regulator. Cell Microbiol. 2007;9(5):1275-83.

43. Queiroz A, Medina-Cleghorn D, Marjanovic O, Nomura DK, Riley LW. Comparative metabolic profiling of mcel operon mutant vs wild-type Mycobacterium tuberculosis strains. Pathog Dis 2015; 73(8):ftv066. doi: 10.1093/femspd/ftv066.

44. Schlesinger LS, Hull SR, Kaufman TM. Binding of the terminal mannosyl units of lipoarabinomannan from a virulent strain of
Mycobacterium tuberculosis to human macrophages. J Immunol. 1994;152(8):4070-79.

45. Strohmeier GR, Fenton MJ. Roles of lipoarabinomannan in the pathogenesis of tuberculosis. Microbes Infect. 1999;1(9):709-17.

46. Mishra AK, Driessen NN, Appelmelk BJ, Besra GS. Lipoarabinomannan and related glycoconjugates: structure, biogenesis and role in Mycobacterium tuberculosis physiology and host-pathogen interaction. FEMS Microbiol Rev. 2011;35(6):1126-57.

47. Nigou J, Gilleron M, Puzo G. Lipoarabinomannans: from structure to biosynthesis. Biochimie. 2003;85(1-2):153-66.

48. Fukuda T, Matsumura T, Ato M, Hamasaki M,Nishiuchi Y, Murakami Y, et al. Critical roles for lipomannan and lipoarabinomannan in cell wall integrity of Mycobacteria and pathogenesis of tuberculosis. MBio. 2013;4(1):e00472-12. doi: 10.1128/mBio.00472-12.

49. Haites RE, Morita YS, McConville MJ, Billman-Jacobe $\mathrm{H}$. Function of phosphatidylinositol in Mycobacteria. J Biol Chem. 2005;280(12):10981-87.

50. Gilleron M, Quesniaux VF, Puzo G. Acylation state of the phosphatidylinositol hexamannosides from Mycobacterium bovis bacillus Calmette Guerin and Mycobacterium tuberculosis H37Rv and its implication in Toll-like receptor response. J Biol Chem. 2003;278(32):29880-89.

51. Jones BW, Means TK, Heldwein KA, Keen MA, Hill PJ, Belisle JT, et al. Different Toll-like receptor agonists induce distinct macrophage responses. J Leukoc Biol. 2001;69(6):1036-44.

52. Dao DN, Kremer L, Guérardel Y, Molano A, Jacobs Jr WR, Porcelli SA, et al. Mycobacterium tuberculosis lipomannan induces apoptosis and interleukin-12 production in macrophages. Infect Immun. 2004;72(4):2067-74.

53. Nigou J, Gilleron M, Rojas M, Garcia LF, Thurnher M, Puzo G. Mycobacterial lipoarabinomannans: modulators of dendritic cell function and the apoptotic response. Microbes Infect. 2002;4(9):94553.

54. Józefowski S, Sobota A, Kwiatkowska K. How Mycobacterium tuberculosis subverts host immune responses. Bioessays. 2008;30(10):943-54.

55. Quesniaux VJ, Nicolle DM, Torres D, Kremer L, Guerardel Y, Nigou J, et al. Toll-like receptor 2 (TLR2)-dependent-positive and TLR2-independent-negative regulation of proinflammatory cytokines by mycobacterial lipomannans. J Immunol. 2004;172(7):4425-34.

56. Krishnan N, Malaga W, Constant P, Caws M, Chau TTH, Salmons $\mathrm{J}$, et al. Mycobacterium tuberculosis lineage influences innate immune response and virulence and is associated with distinct cell envelope lipid profiles. PLoS One. 2011;6(9):e23870. doi: 10.1371/ journal.pone.0023870.

57. Ryll R, Kumazawa Y, Yano I. Immunological properties of trehalose dimycolate (cord factor) and other mycolic acid-containing glycolipids - a review. Microbiol Immunol. 2001;45(12):801-11.

58. Cooper AM. Cell-mediated immune responses in tuberculosis. Annu Rev Immunol. 2009;27(1):393-422.

59. van der Wel N, Hava D, Houben D, Fluitsma D, van Zon M, Pierson J, et al. M. tuberculosis and M. leprae translocate from the phagolysosome to the cytosol in myeloid cells. Cell. 2007;129:1287-98.

60. Barral DC, Brenner MB. CD1 antigen presentation: how it works. Nat Rev Immunol. 2007;7:929-41.

61. Karakousis PC, Bishai WR, Dorman SE. Mycobacterium tuberculosis cell envelope lipids and the host immune response. Cell Microbiol. 2004;6(2):105-16.

62. Mendum TA, Wu H, Kierzek AM, Stewart GR. Lipid metabolism and Type VII secretion systems dominate the genome scale 
virulence profile of Mycobacterium tuberculosis in human dendritic cells. BMC Genomics. 2015;16(1):372.

63. Hatzios SK, Schelle MW, Holsclaw CM, Behrens CR, Botyanszki $\mathrm{Z}$, Lin FL, et al. PapA3 is an acyltransferase required for polyacyltrehalose biosynthesis in Mycobacterium tuberculosis. J Biol Chem. 2009;284(19):12745-51.

64. Dubey VS, Sirakova TD, Kolattukudy PE. Disruption of msl3 abolishes the synthesis of mycolipanoic and mycolipenic acids required for polyacyltrehalose synthesis in Mycobacterium tuberculosis $\mathrm{H} 37 \mathrm{Rv}$ and causes cell aggregation. Mol Microbiol. 2002;45(5):1451-59.

65. Sirakova TD, Thirumala AK, Dubey VS, Sprecher H, Kolattukudy PE. The Mycobacterium tuberculosis pks2 gene encodes the synthase for the hepta- and octamethyl-branched fatty acids required for sulfolipid synthesis. J Biol Chem. 2001;276(20):16833-39.

66. Besra GS, Bolton RC, McNeil MR, Ridell M, Simpson KE, Glushka $\mathrm{J}$, et al. Structural elucidation of a novel family of acyltrehaloses from Mycobacterium tuberculosis. Biochemistry. 1992;31(40):9832-37.

67. Saavedra R, Segura E, Leyva R, Esparza LA, López-Marin LM. Mycobacterial di-O-acyl-trehalose inhibits mitogen- and antigeninduced proliferation of murine $\mathrm{T}$ cells in vitro. Clin Vaccine Immunol. 2001;8(6):1081-88.

68. Rousseau C, Neyrolles O, Bordat Y, Giroux S, Sirakova TD, Prevost $\mathrm{MC}$, et al. Deficiency in mycolipenate- and mycosanoate-derived acyltrehaloses enhances early interactions of Mycobacterium tuberculosis with host cells. Cell Microbiol. 2003;5(6):405-15.

69. Middlebrook G, Coleman CM, Schaefer WB. Sulfolipid from Virulent Tubercle Bacilli. Proc Natl Acad Sci USA. 1959;45(12): 1801-04.

70. Mougous JD, Petzold CJ, Senaratne RH, Lee DH, Akey DL, Lin FL, et al. Identification, function and structure of the mycobacterial sulfotransferase that initiates sulfolipid-1 biosynthesis. Nat Struct Mol Biol. 2004;11(8):721-29.

71. Kumar P, Schelle MW, Jain M, Lin FL, Petzold CJ, Leavell MD, et al. PapA1 and PapA2 are acyltransferases essential for the biosynthesis of the Mycobacterium tuberculosis virulence factor sulfolipid-1. Proc Natl Acad Sci USA. 2007;104(27):11221-26.

72. Converse SE, Mougous JD, Leavell MD, Leary JA, Bertozzi CR, Cox JS. MmpL8 is required for sulfolipid-1 biosynthesis and Mycobacterium tuberculosis virulence. Proc Natl Acad Sci USA. 2003;100(108):6121-26.

73. Goren MB, D'Arcy Hart P, Young MR, Armstrong JA. Prevention of phagosome-lysosome fusion in cultured macrophages by sulfatides of Mycobacterium tuberculosis. Proc Natl Acad Sci USA. 1976;73(7):2510-14.

74. Gilleron M, Stenger S, Mazorra Z, Wittke F, Mariotti S, Böhmer $\mathrm{G}$, et al. Diacylated sulfoglycolipids are novel mycobacterial antigens stimulating CD1-restricted $\mathrm{T}$ cells during infection with Mycobacterium tuberculosis. J Exp Med. 2004;199(5):649-59.

75. Pabst MJ, Gross JM, Brozna JP, Goren MB. Inhibition of macrophage priming by sulfatide from Mycobacterium tuberculosis. J Immunol. 1988;140(2):634-40.

76. Zhang L, English D, Andersen BR. Activation of human neutrophils by Mycobacterium tuberculosis-derived sulfolipid-1. J Immunol. 1991;146(8):2730-36.

77. Rousseau C, Turner OC, Rush E, Bordat Y, Sirakova TD, Kolattukudy PE, et al. Sulfolipid deficiency does not affect the virulence of Mycobacterium tuberculosis $\mathrm{H} 37 \mathrm{Rv}$ in mice and guinea pigs. Infect Immun. 2003;71(8):4684-90.
78. Kato M, Goren MB. Synergistic action of cord factor and mycobacterial sulfatides on mitochondria. Infect Immun. 1974;10(4):733-41.

79. Domenech P, Reed MB, Dowd CS, Manca C, Kaplan G, Barry 3rd CE. The role of MmpL8 in sulfatide biogenesis and virulence of Mycobacterium tuberculosis. J Biol Chem. 2004;279(20):21257-65.

80. Cox JS, Chen B, McNeil M, Jacobs Jr WR. Complex lipid determines tissue-specific replication of Mycobacterium tuberculosis in mice. Nature. 1999;402(6757):79-83.

81. Trivedi OA, Arora P, Vats A, Ansari MZ, Tickoo R, Sridharan V, et al. Dissecting the mechanism and assembly of a complex virulence mycobacterial lipid. Mol Cell. 2005;17(5):631-43.

82. Trivedi OA, Arora P, Sridharan V, Tickoo R, Mohanty D, Gokhale RS. Enzymic activation and transfer of fatty acids as acyl-adenylates in mycobacteria. Nature. 2004;428(6981):441-45.

83. Goren MB, Brokl O, Schaefer WB. Lipids of putative relevance to virulence in Mycobacterium tuberculosis: phthiocerol dimycocerosate and the attenuation indicator lipid. Infect Immun. 1974;9(1):150-58.

84. Liu J, Barry 3rd CE, Besra GS, Nikaido H. Mycolic acid structure determines the fluidity of the mycobacterial cell wall. J Biol Chem. 1996;271(47):29545-51.

85. Camacho LR, Constant P, Raynaud C, Laneelle MA, Triccas JA, Gicquel B, et al. Analysis of the phthiocerol dimycocerosate locus of Mycobacterium tuberculosis. Evidence that this lipid is involved in the cell wall permeability barrier. J Biol Chem. 2001;276(23):19845-54.

86. Rousseau C, Winter N, Pivert E, Bordat Y, Neyrolles O, Avé P, et al. Production of phthiocerol dimycocerosates protects Mycobacterium tuberculosis from the cidal activity of reactive nitrogen intermediates produced by macrophages and modulates the early immune response to infection. Cell Microbiol. 2004;6(3):277-87.

87. Astarie-Dequeker C, Le Guyader L, Malaga W, Seaphanh FK, Chalut C, Lopez A, et al. Phthiocerol dimycocerosates of $M$. tuberculosis participate in macrophage invasion by inducing changes in the organization of plasma membrane lipids. PLoS Pathog. 2009;5(2):e1000289. doi: 10.1371/journal.ppat.1000289.

88. Pérez E, Samper S, Bordas Y, Guilhot C, Gicquel B, Martín C. An essential role for phoP in Mycobacterium tuberculosis virulence. Mol Microbiol. 2001;41(1):179-87.

89. Gonzalo Asensio J, Maia C, Ferrer NL, Barilone N, Laval F, Soto $\mathrm{CY}$, et al. The virulence-associated two-component PhoP-PhoR system controls the biosynthesis of polyketide-derived lipids in Mycobacterium tuberculosis. J Biol Chem. 2006;281(3):1313-16.

90. Galagan JE, Minch K, Peterson M, Lyubetskaya A, Azizi E, Sweet $\mathrm{L}$, et al. The Mycobacterium tuberculosis regulatory network and hypoxia. Nature. 2013;499(7457):178-83.

91. Singh A, Crossman DK, Mai D, Guidry L, Voskuil MI, Renfrow $\mathrm{MB}$, et al. Mycobacterium tuberculosis WhiB3 maintains redox homeostasis by regulating virulence lipid anabolism to modulate macrophage response. PLoS Pathog. 2009; 5(8):e1000545. doi: 10.1371/journal.ppat.1000545.

92. Cunningham AF, Spreadbury CL. Mycobacterial stationary phase induced by low oxygen tension: cell wall thickening and localization of the 16-kilodalton alpha-crystallin homolog. J Bacteriol. 1998;180(4):801-08.

93. Dunphy KY, Senaratne RH, Masuzawa M, Kendall LV, Riley LW. Attenuation of Mycobacterium tuberculosis functionally disrupted in a fatty acyl-CoA synthetase gene fadD5. J Infect Dis. 2010;201(8):1232-39. 